\title{
Leiomyoma of the duodenum as a cause of recurrent post-gastrectomy bleeding
}

\author{
J. L. DAWSON ${ }^{1}$ \\ From St. James's Hospital, Balham, London
}

EDITORIAL SYNOPSIS A patient with recurrent melaena over a period of four years is reported. He underwent four laparotomies. At the fourth operation a leiomyoma of the second part of the duodenum was found and successfully resected. The clinical features of leiomyomatous tumours of the duodenum are reviewed, and recurrent unexplained gastrointestinal haemorrhage is emphasized as a common manifestation.

Tumours derived from the muscle coat of the duodenum are rare, and successful surgical treatment is even rarer (Weinstein and Roberts, 1953; Starr and Dockerty, 1955). A case of leiomyoma of the duodenum is presented because it illustrates some of the clinical features of leiomyomata, as well as an unusual pitfall which was encountered in the diagnosis of recurrent gastrointestinal haemorrhage. This case is one of the few recorded leiomyomatous lesions of the second part of the duodenum which have been successfully resected (Weinstein and Roberts, 1953).

\section{CASE REPORT}

NOVEMBER 1957 A 36-year-old man with no past history of dyspepsia was admitted to his local hospital with severe melaena. The melaena persisted and laparotomy was performed but no obvious cause for the bleeding could be found. As there was blood in the duodenum and small bowel, the duodenum was opened and a bleeding point on the medial wall of the second part was found and under-run. He made an uneventful recovery.

SEPTEMBER 1958 The patient was re-admitted to his local hospital with a severe, persistent melaena which necessitated a laparotomy. No causal lesion was found, and a 'blind' Polya partial gastrectomy was done. The melaena continued for several days and then stopped. His further convalescence was uneventful.

AUGUST 1959 He was admitted to hospital with a further melaena, and a barium meal at this time showed normal post-gastrectomy appearances.

SEPTEMBER $1959 \mathrm{He}$ was transferred to St. James's Hospital, where oesophagoscopy showed a normal

'Present address: King's College Hospital, Denmark Hill, London, S.E.5. oesophagus. Gastroscopy showed several black unabsorbed sutures hanging from the gastro-jejunal anastomosis. Those which could be seen were removed (using an attachment to the gastroscope) but it was thought possible that some sutures might not have been removed. At this stage it was assumed that the recurrent haemorrhages were due to ulceration around the unabsorbed sutures used in the gastro-jejunal anastomosis (Tanner, 1951).

JANUARY 1960 At St. James's Hospital gastroscopy showed that some unabsorbed sutures were still present, but as he had had no bleeding for six months he was kept under review.

OCTOBER 1960 The patient was re-admitted to his local hospital with melaena, which stopped spontaneously. $\mathrm{He}$ was again transferred to St. James's Hospital and underwent laparotomy. This time the stomach was opened, all the unabsorbed sutures were removed, and the gastrotomy was closed with catgut. The descending limb of the duodenum was not examined.

OCTOBER 1961 He was re-admitted to his local hospital with severe melaena $(\mathrm{Hb} 30 \%)$ and after transfusion the melaena stopped. The patient was transferred to St. James's Hospital. It was now obvious that the bleeding was not due to unabsorbed sutures.

JANUARY 1962 Laparotomy was performed with careful dissection of the blind loop. A lobulated vascular tumour, about $2 \frac{1}{2}$ in. diameter, was found in the head of the pancreas (Figs. 1 and 2). There were no obvious metastases in the regional nodes or liver. Pancreaticduodenectomy was performed with some difficulty because the tumour was adherent to the portal vein. The afferent limb of the jejunum was resected with the duodenum and closed flush with the stomach. The common bile duct and body of the pancreas were implanted into a loop of jejunum, and entero-anastomosis 


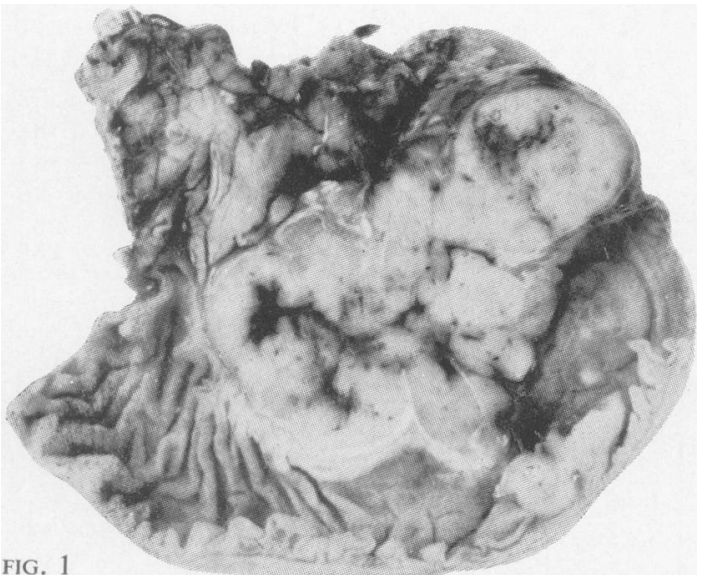

FIG. 1. The operation specimen, cut in coronal section and viewed from behind, showing the tumour which had narrowed and ulcerated into the second part of the duodenum. The tumour, which was firm amd lobulated, occupied the head of the pancreas and measured $2 \frac{1}{2}$ in. in diameter. The cut surface was whitish grey.

FIG. 2. Photomicrograph of a histological section of the tumour $(\times 70)$. The tumour was composed of welldifferentiated spindle cells with eosinophilic cytoplasm. Mitoses were scanty and there was no suggestion of malignancy.

FIG. 1

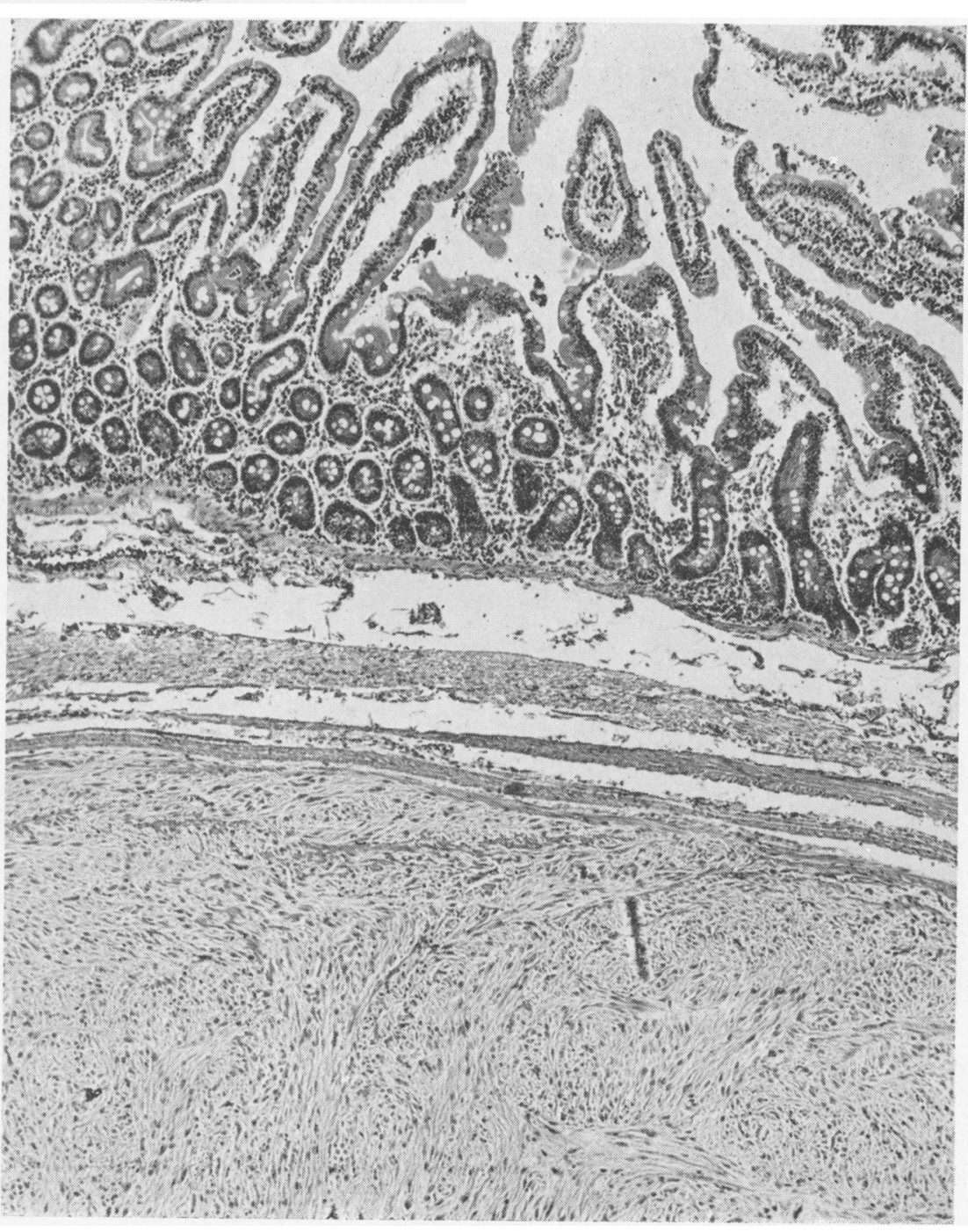

FIG. 2 
was performed between the proximal and distal limbs of this loop. Apart from a slight pancreatic fistula which persisted for about three weeks, the patient made an uneventful recovery.

$\mathrm{He}$ was alive and well when seen 14 months after operation. He had gained $16 \mathrm{lb}$. in weight and was working full time. He was having no treatment and passing two or three soft stools each day.

\section{CLINICAL FEATURES}

Although leiomyomas and leiomyosarcomas of the duodenum are rare, sufficient cases bave heen reported to enable their characteristic behaviour to be studied (Foshee and McBride, 1939; Golden and Stout, 1941; Olson, Dockerty, and Gray, 1951; Weinstein and Roberts, 1953; Starr and Dockerty, 1955).

Gastrointestinal haemorrhage is the commonest manifestation of these tumours. It occurs in almost every case and may be the only symptom. In small tumours the bleeding is often intermittent and even in malignant tumours may be spread over several years (Golden and Stout, 1941). Bleeding from large tumours may be progressive and fatal because the walls of the cavity are held open by rigid tumour tissue (Smith, 1937).

Pain, which may mimic that of duodenal ulcer, commonly occurs with small tumours (Rankin and Newell, 1933), pain due to involvement of surrounding structures with more advanced tumours (Starr and Dockerty, 1955). Occasionally rupture of a necrotic tumour into the peritoneal cavity produces diffuse peritonitis (Golden and Stout, 1941). Sometimes a necrotic tumour ruptures into the bowel lumen and subsequent barium studies show barium outside the gut lumen (Starr and Dockerty, 1955; Golden and Stout, 1941).

Jaundice secondary to ampullary obstruction has been recorded on four occasions (Wendel, 1925; Seymour and Gould, 1936; McLean, 1948; Swartz and Eckman, 1951), and steatorrhoea due to pancreatic duct obstruction only once (Shackelford, Fisher, and Firor, 1942).

Physical examination may be normal. Barium studies occasionally show a filling defect or barium outside the gut lumen, but more often show no abnormality (Coombes, 1958).

Thus gastrointestinal bleeding without physical or radiological abnormality is a common mode of presentation of these tumours, and laparotomy may be necessary to make the diagnosis.

\section{TREATMENT}

Surgical excision offers the only hope of cure as these tumours are resistant to radium. Because of early involvement of adjacent structures, successful removal of leiomyomas and leiomyosarcomas of the second part of the duodenum is rare, and only three successful resections have previously been recorded (Shackelford, Fisher, and Firor, 1942; Schwartz, Swingle, and Raymond, 1951; Swartz and Eckman, 1951).

\section{COMMENT}

In the present case, the leiomyoma was no doubt small and obscured by the head of the pancreas at the time of the first two laparotomies. This is most unusual, as in all previously recorded cases the lesion has been obvious at operation once it had reached the stage of causing bleeding. Following the Polya gastrectomy, barium studies were of no help in the diagnosis as the lesion lay adjacent to the closed duodenal stump and therefore did not show up.

It is well established that non-absorbable sutures used in the 'all-coats' layer of a gastro-jejunal anastomosis cause recurrent ulceration and bleeding (Tanner, 1951; Bradbeer, 1962), and consequently, the discovery of non-absorbable sutures in this patient was a complete 'red herring' and delayed the correct diagnosis for about eighteen months.

Whether this tumour is benign or malignant will only be answered by the patient's future course. Its rather large size was somewhat suggestive of malignancy, but the long history before resection and the patient's subsequent progress are against it. The long intervals between the bouts of haemorrhage is most unusual, but no doubt the defunctioning of the duodenal loop after gastrectomy may account for them.

Finally it is worth emphasizing the patient's excellent health at present, despite pancreaticduodenectomy.

I wish to thank Mr. N. C. Tanner for his helpful criticism and also for permission to publish his case; Dr. L. W. Proger for the pathological report and the photomicrograph; and Miss. E. M. Mason for the photograph of the specimen.

\section{REFERENCES}

Bradbeer, J. (1962). Complications of the use of continuous nonabsorbable sutures in gastric operations. Proc. roy. Soc. Med., $55,448-449$.

Coombes, W. N. (1958). Leiomyoma of the duodenum. Ibid., 46, 127-129.

Foshee, J. C., and McBride, W. P. L. (1939). Leiomyosarcoma of the duodenum. J. Amer. med. Ass., 112, 2497-2500.

Golden, T., and Stout, A. P. (1941). Smooth muscle tumors of the gastrointestinal tract and retroperitoneal tissues. Surg. Gynec. Obstet., 73, 784-810.

McLean, R. B. (1948). Malignancies of the duodenum. Sth. Surg., 14, $430-455$. 
Olson, J. D., Dockerty, M. B., and Gray, H. K. (1951). Benign tumours of the small bowel. Ann. Surg., 134, 195-204.

Rankin, F. W., and Newell, C. E. (1933). Benign tumors of the small intestine: report of 24 cases. Surg. Gynec. Obstet., 57, 501-507.

Schwartz, N. H., Swingle, R. C., and Raymond, E. A. (1951). Malignant tumors of the duodenum. Arch. intern. Med., 87, 410-417.

Seymour, W. J., and Gould, S. E. (1936). Leiomyosarcoma of the duodenum. Amer. J. Cancer, 28, 572-578.

Shackelford, R. T., Fisher, A. M., and Firor, W. B. (1942). Duodenal tumor of unusual character. Ann. Surg., 116, 864-873.
Smith, O. N. (1937). Leoimyoma of the small intestine. Amer. J. med. Sci., 194, 700-707.

Starr, G. F., and Dockerty, M. B. (1955). Leiomyomas and leiomyosarcomas of the small intestine. Cancer (Philad.), 8, 101-111.

Swartz, W. T., and Eckman, W. G., Jr. (1951). A case report of leiomyosarcoma of the duodenum. Surgery, 29, 581-586.

Tanner, N. C. (1951). Operative methods in the treatment of peptic ulcer. Edinb. med. J., 58, 279-292.

Weinstein, M., and Roberts, M. (1953). Leiomyosarcoma of the duodenum. Arch. Surg., 66, 318-328.

Wendel, (1925). Ueber Geschwülste des Dünndarmes. Münch. med. Wschr., 72, 285-286.

\section{The February 1964 Issue}

\section{THE FEBRUARY 1964 ISSUE CONTAINS THE FOLLOWING PAPERS}

Course and prognosis of ulcerative colitis FELICITY C. EDWARDS and S. C. TRUELOVE

\section{Part III Complications}

Part IV Carcinoma of the colon

Autoimmune serological studies in chronic gastritis and pernicious anaemia IAN R. MACKAY

Vitamin $\mathbf{B}_{12}$ deficiency in chronic gastritis $\mathbf{I}$. J. wooD, M. RALSTON, B. UNGAR, and D. C. COWLING

Absorption of iron by gastrectomized rats J. s. W. WHITEHEAD and R. M. BANNERMAN with the technical assistance of J. HALFACREE

The first description of tropical sprue c. C. BоoTH

Small intestinal mucosal patterns of coeliac disease and idiopathic steatorrhoea seen in other situations R. R. W. TOWNLEY, M. H. CASS, and CHARLOTTE M. ANDERSON

Oestrogen metabolism and excretion in liver disease J. B. BROWN, G. P. CREAN, and JEAN GINSBURG

Jejunal mucosal appearances after total gastrectomy J. M. JOHNSTONE and J. F. ADAMS

The distribution of pyloric mucosa in partial gastrectomy specimens A. C. B. DEAN and M. K. MASON
A study of the role of proteinorrhoea (protein-losing gastro-enteropathy) in bilharzial hepatic fibrosis $\mathbf{M}$. EL-SAYED and M. ESSAM FIKRY

Potentiation between Urecholine and gastrin extract and between Urecholine and histamine in the stimulations of Heidenhain pouches IAIN E. GILLESPIE and MORTON I. GROSSMAN

Appearances of the stools after the introduction of blood into the caecum R. G. LUKE, W. LEES, and J. RUDICK

Massive oesophagostomiasis of the colon J. E. JACQUES and J. B. LYNCH

Peptic ulcer, gastric secretion, and body build J. H. BARON

Pressure rupture and spontaneous perforation of the oesophagus DOUGLAS H. CLARK and H. I. TANKEL

Endoradiosonde study of propulsion and pressure activity induced by test meals, Prostigmine, and diphenoxylate in the small intestine F. BÁRÁNY and BERTIL JACOBSON

\section{Methods and techniques}

The endomotorsonde G. VANTRAPPEN, J. D'HAENS, S. VERBEKE, and J. VANDENBROUCKE

Fluorescence microscopy in colonic exfoliative cytology D. J. OAKLAND

Copies are still available and may be obtained from the PUBLISHING MANAGER, BRITISH MEDICAL ASSOCIATION, TAVISTOCK SQUARE, W.C.I., price 18s. 6D. 